\title{
Evaluation of productivity and volatile compound quality of Artemisia absinthium L. planted in Valle Camonica (Italy)
}

\author{
Monica Bononi, Anna Giorgi, Maurizio Cocucci and Fernando Tateo* \\ Dipartimento di Produzione Vegetale, Agriculture Faculty, University of Milan, Via G Celoria 2, 20133 Milan, Italy
}

\begin{abstract}
This work shows results from a check on Artemisia absinthium L. productivity in Valle Camonica (Italy). The aim of this check was to demonstrate whether products of adequately consistent quality may be obtained when using specific implant material with invariable variety characteristics. Altitude, Maipex mulch treatment and soil characteristics appear to influence the production data: in particular, at altitudes of $1000 \mathrm{~m}$ asl and higher the mean production results increased, and a lower level of $\mathrm{Ca}$ and cation exchange capacity have a negative effect on Maipex treatment. On the other hand, no differences correlated to altitude were found for representative volatile compounds in free soil, and a non-significance of differences in quantitative composition of volatile compounds may be assumed. The limited variability of the volatile fraction guarantees sufficient botanical equivalence of the various products.

(C) 2006 Society of Chemical Industry
\end{abstract}

Keywords: Artemisia absinthium L.; Valle Camonica; Regione Lombardia; herb productivity; abundance indexes; volatile compounds

\section{INTRODUCTION}

Interest in Artemisia absinthium L. cultivation in Valle Camonica, Italy, arises from the aim of exploitation of mountain territories, as harvesting of wild-growing aromatic herbs is very expensive today. On the other hand, for industrial applications of extracts obtained from aromatic plants, it is important to ensure a relatively consistent quality of herbs to be used in different sectors such as alcoholic and non-alcoholic beverages as well as cosmetics.

The most widespread chemotypes of $A$. absinthium L., according to Chialva et al., ${ }^{1,2}$ can be identified as follows: (i) predominance of cis-epoxyocimene $(25-54 \%)$, as compared to $\alpha$ - and $\beta$ thujone (max. $8 \%$ ); (ii) abundance of thujone; (iii) abundance of chrysanthenyl acetate; and (iv) abundance of sabinyl acetate. Also, according to Carnat et al., ${ }^{3}$ a chemotype with predominance of cischrysanthenol can easily be found, and Ariño et al. ${ }^{4}$ showed data corresponding to a chemotype with more than $50 \%$ of cis-epoxyocimene + chrysanthenyl acetate $(25-65 \%$ the former; $15-50 \%$ the latter).

The Vegetal Production Department at the Agriculture Faculty of the University of Milan has been developing various experiments for production of different officinal plants in experimental fields located in Valle Camonica. It was considered useful to perform plantation trials for altitude and soil characteristics and qualitative tests using $A$. absinthium $\mathrm{L}$. from differently located fields. The aim was to verify whether, though at different altitudes, herbs may be produced which can give rise to standardizable extracts.

\section{EXPERIMENTAL}

Results from experiences reported in this work were referred to a trial which had been started in February 2003, and relevant data were obtained from the 2003 harvest. Experimental fields were located in Pellalepre-Darfo (240 m asl), Sonico (650 m asl), Borno (1000 m asl), Monno (1100 $\mathrm{m}$ asl) and Saviore dell'Adamello (1250 $\mathrm{m}$ asl). The transplanting mode was applied to obtain experimental cultivations. Plants were purchased at the garden centre 'Etablissement Horticole' at Saillo (Switzerland). This is a centre for propagation of cultivars selected by RAC, a federal Swiss research group.

The chemotype object of our implant trials was one with marked abundance of $\alpha+\beta$-thujone. Abundance indexes between some volatile compounds and ratios between the area counts of volatile compounds were adopted as comparison indexes for volatile compounds. Data were produced by gas chromatography (GC), and identification of peaks was performed by gas chromatography-mass spectrometry (GC-MS).

Data for height reached from stems and yields in dried material, expressed as $\mathrm{g} \mathrm{m}^{-2}$, were also compared. In this work results from in-field cultivation obtained both (i) without fertilizing, and (ii) without

* Correspondence to: Fernando Tateo, Dipartimento di Produzione Vegetale, Agriculture Faculty, University of Milan, Via G Celoria 2, 20133 Milan, Italy E-mail: fernando.tateo@unimi.it

(Received 17 November 2005; revised version received 18 March 2006; accepted 6 July 2006)

Published online 2 October 2006; DOI: 10.1002/jsfa.2653 
Table 1. Productivity data for Artemisia absinthium L. grown at different altitudes under different soil conditions: free soil and soil with Maipex mulch

\begin{tabular}{lccccc}
\hline & \multicolumn{2}{c}{ Free soil } & & \multicolumn{2}{c}{$\begin{array}{c}\text { Soil with Maipex } \\
\text { mulch }\end{array}$} \\
\cline { 2 - 3 } & $\begin{array}{c}\text { Stem } \\
\text { height }\end{array}$ & $\begin{array}{c}\text { Dried } \\
\text { material }\end{array}$ & & $\begin{array}{c}\text { Stem } \\
\text { height }\end{array}$ & $\begin{array}{c}\text { Dried } \\
\text { material }\end{array}$ \\
location & $(\mathrm{cm})$ & $\left(\mathrm{g} \mathrm{m}^{-2}\right)$ & & $(\mathrm{cm})$ & $\left(\mathrm{g} \mathrm{m}^{-2}\right)$
\end{tabular}

fertilizing but with Maipex mulch (interlaced polyethylene) were considered.

\section{Productivity}

Mean productivity data relating to five experimental cultivations (stem height and yield in dried material, $g$ $\mathrm{m}^{-2}$ ) are reported in Table 1 .

\section{Soil analysis}

Five soil samples were taken from each field: Darfo, Sonico, Borno, Monno and Saviore. Coring was performed in conformity with standard methodology outlined in Official Methods of Chemical Analysis of Soils. ${ }^{5}$ Means for chemical characteristic values corresponding to each field are reported in Table 2.

\section{Sample preparation for GC and GC-MS analysis of volatile compounds}

Aerial parts of herb samples were harvested manually in summer and air-dried (ambient temperature $30-40{ }^{\circ} \mathrm{C}$ ). One hundred grams of each sample (leaves and inflorescences) belonging to each field were finely crushed and mixed: extraction was carried out on $10 \mathrm{~g}$ aliquots (three aliquots from each mixture were considered). The extraction was performed by dynamic infusion (3 days) in ethanol $95 \% \mathrm{v} / \mathrm{v}(50 \mathrm{~mL})$. The three extracts deriving from each group of aliquots were mixed, treated in an ultrasonic bath for $15 \mathrm{~min}$ and centrifuged at $4000 \mathrm{rpm}$. After filtration (Millipore $0.45 \mu \mathrm{m}$ ), they were analysed by GC and GC-MS.

The final extracts $(2 \mu \mathrm{L})$ were directly injected into a GC $8000^{\text {TOP }}$ gas chromatograph (CE Instrument, Milan, Italy), equipped with flame ionization detector, in splitless mode for $1 \mathrm{~min}$ and then in split mode 1:100. The column was a Supelcowax ${ }^{\mathrm{TM}} 10$, polar poly(ethylene glycol) capillary column $(60 \mathrm{~m} \times$ $0.32 \mathrm{~mm}$ i.d., $0.25 \mu \mathrm{m}$ film thickness; Supelco, Milan, Italy), and $\mathrm{H}_{2}$ was used as a carrier gas (pressure = $30 \mathrm{kPa}$ ).

The temperature programme was as follows: isothermal for $1 \mathrm{~min}$ at $60^{\circ} \mathrm{C}$, increasing at a rate of $3^{\circ} \mathrm{C} \min ^{-1}$ to $240^{\circ} \mathrm{C}$. Injector temperature was kept at $230^{\circ} \mathrm{C}$ and the detector temperature was $260^{\circ} \mathrm{C}$.

GC-MS analyses were carried out in order to confirm identification of peaks, which were considered to be useful for the comparison. A Shimadzu 2010 gas chromatograph coupled to a Shimadzu QP 2010 quadrupole mass spectrometer (Shimadzu, Milan, Italy), was used. The GC column was a Supelcowax ${ }^{\mathrm{TM}}$ 10 fused-silica capillary column $(30 \mathrm{~m} \times 0.25 \mathrm{~mm}$ i.d., $0.25 \mu \mathrm{m}$ film thickness). Helium was used as a carrier gas at $57 \mathrm{kPa}$ constant pressure (column: isothermal for $1 \mathrm{~min}$ at a flow rate of $1 \mathrm{~mL} \mathrm{~min}^{-1}$ ). The temperature programme was as follows: $60^{\circ} \mathrm{C}$, increasing at a rate of $10^{\circ} \mathrm{C} \min ^{-1}$ to $240^{\circ} \mathrm{C}$. The injector temperature was kept on $220^{\circ} \mathrm{C}$, the detector temperature was $240^{\circ} \mathrm{C}$, and voltage was set at $0.9 \mathrm{kV}$. Injection volume was $2 \mu \mathrm{L}$ in splitless mode for $1 \mathrm{~min}$ and then in split mode $1: 100$.

The mass spectrometer was operated in EI mode, and positive ions at $70 \mathrm{eV}$ were recorded with a scan range from $m / z 40$ to $m / z 300$ at 2 scans s$^{-1}$.

GC data were reported as 'abundance indexes' $\left(A_{\mathrm{n}}\right)$, which may be defined as follows, considering $\alpha$-phellandrene as a reference peak. An analogous criterion is currently being applied to characterizations similar to or other than GC or GC/MS: ${ }^{6}$

$$
A_{\mathrm{n}}=C_{\mathrm{n}} / C_{\alpha-\text { phell }}
$$

Table 2. Characteristics of soils in experimental fields

\begin{tabular}{|c|c|c|c|c|c|}
\hline & \multicolumn{5}{|c|}{ Field location } \\
\hline & Darfo (240 m asl) & Sonico (650 m asl) & Borno (1000 m asl) & Monno (1100 m asl) & Saviore (1250 m asl) \\
\hline $\mathrm{pH}$ & 5.9 & 6.1 & 7.3 & 5.8 & 5.6 \\
\hline C org. (\%) & 2.7 & 2.8 & 3.2 & 2.0 & 6.1 \\
\hline P Olsen (ppm) & - & - & 61.2 & - & - \\
\hline P Bray Kurtz (ppm) & 39.9 & 16.4 & - & 13.1 & 8.7 \\
\hline $\mathrm{CEC}^{\mathrm{a}}\left(\mathrm{cmol}^{+} \mathrm{kg}^{-1}\right)$ & 17.7 & 16.9 & 23.5 & 14.1 & 31.1 \\
\hline Ca (ppm) & 3498 & 2451 & 6743 & 1419 & 2632 \\
\hline Mg (ppm) & 231 & 117 & 122 & 162 & 149 \\
\hline K (ppm) & 216 & 101 & 172 & 142 & 109 \\
\hline Sand (\%) & 61.3 & 62.8 & 45.4 & 64.8 & 58.7 \\
\hline Silt (\%) & 35.1 & 35.2 & 45.1 & 32.7 & 38.6 \\
\hline Clay (\%) & 3.6 & 2.0 & 9.5 & 2.5 & 2.7 \\
\hline
\end{tabular}

a CEC, cation exchange capacity. 
where $C_{\mathrm{n}}=$ single compound area count and $C_{\alpha-\text { phell }}=\alpha$-phellandrene area count.

Adopting a ratio $\left(R_{\mathrm{n}}\right)$ between the area count of various individual volatile compounds and the area count of the most representative compound in the chromatogram ( $\alpha+\beta$-thujone), a further improved comparison may be obtained between different extracts.

Both $\Delta_{\max }$ and $\Delta_{\min }$ values and mean values $(M)$ are deduced from ratios $R_{\mathrm{n}}$.

\section{RESULTS AND DISCUSSION}

Based on data for $A$. absinthium L. growth in the different soils considered for the trial, as highlighted in Tables 1 and 2, the following conclusions can be drawn:

1. Mean production of stem and dried material below $1000 \mathrm{~m}$ asl, on free soil, was significantly less than in plants grown on soils located at $1000 \mathrm{~m}$ asl and higher; production, on free soil and at lower altitudes than $1000 \mathrm{~m}$ asl, was appreciably increased when Maipex mulch was used.

2. At an altitude of $1000 \mathrm{~m}$ asl and higher, mean production of stem and dried material was affected by soil characteristics, as well as Maipex mulch treatment; a lower level of $\mathrm{Ca}$ and cation exchange capacity (CEC) was shown to have a negative effect both on free soil and on soil covered with Maipex mulch.

3. Organic carbon abundance (\%) and a high CEC value were significant factors for stem and dried material growth and increased the altitude effect.

'Abundance indexes' are shown in Table 3 (for free soil) and Table 4 (for soil with Maipex mulch). From evaluation of the data, no differences in abundance indexes directly correlated to 'altitude' and 'soil quality' were found. A definite predominance of $\alpha$ and $\beta$-thujone was invariably identified. In most cases,

Table 3. Evaluations by GC and GC-MS chromatograms of some representative volatile compounds in plants grown in free soil. The compound area counts were reported as $A_{\mathrm{n}}$ (abundance indexes) according to the formula in the text

\begin{tabular}{|c|c|c|c|c|c|}
\hline \multirow[b]{2}{*}{ Compound } & \multicolumn{5}{|c|}{ Field location } \\
\hline & $\begin{array}{c}\text { Darfo } \\
\text { (240 m } \\
\text { asl) }\end{array}$ & $\begin{array}{c}\text { Sonico } \\
\text { (650 m } \\
\text { asl) }\end{array}$ & $\begin{array}{c}\text { Borno } \\
\text { (1000 m } \\
\text { asl) }\end{array}$ & $\begin{array}{c}\text { Monno } \\
\text { (1100 m } \\
\text { asl) }\end{array}$ & $\begin{array}{c}\text { Saviore } \\
\text { (1250 m } \\
\text { asl) }\end{array}$ \\
\hline$\alpha$-Phellandrene & 1.00 & 1.00 & 1.00 & 1.00 & 1.00 \\
\hline 1,8-Cineole & 0.64 & 0.21 & 0.72 & 0.31 & 0.72 \\
\hline p-Cymene & 0.40 & 0.44 & 0.42 & 0.39 & 0.96 \\
\hline Linalool & 0.18 & 0.07 & 0.15 & 0.09 & 0.16 \\
\hline$\alpha$-Thujone & 1.42 & 0.42 & 0.80 & 0.75 & 0.72 \\
\hline$\beta$-Thujone & 37.73 & 13.10 & 19.75 & 18.46 & 19.50 \\
\hline$\alpha$-Bisabolol & 1.05 & 0.28 & 0.23 & 0.48 & 1.45 \\
\hline$\Sigma$-Terpenes ${ }^{\mathrm{a}}$ & 1.69 & 1.41 & 2.16 & 2.01 & 2.63 \\
\hline
\end{tabular}

${ }^{\mathrm{a}} \Sigma$-Terpenes $=$ sabinene $+\beta$-pinene $+p$-cymene.
Table 4. Evaluations by GC and GC-MS chromatograms of some representative volatile compounds in plants grown in soil with Maipex mulch. The compound area counts were reported as $A_{n}$ (abundance indexes) according to the formula in the text

\begin{tabular}{|c|c|c|c|c|c|}
\hline \multirow[b]{2}{*}{ Compound } & \multicolumn{5}{|c|}{ Field location } \\
\hline & $\begin{array}{c}\text { Darfo } \\
\text { (240 m } \\
\text { asl) }\end{array}$ & $\begin{array}{c}\text { Sonico } \\
\text { (650 m } \\
\text { asl) }\end{array}$ & $\begin{array}{c}\text { Borno } \\
\text { (1000 m } \\
\text { asl) }\end{array}$ & $\begin{array}{c}\text { Monno } \\
\text { (1100 m } \\
\text { asl) }\end{array}$ & $\begin{array}{c}\text { Saviore } \\
\text { (1250 m } \\
\text { asl) }\end{array}$ \\
\hline$\alpha$-Phellandrene & 1.00 & 1.00 & 1.00 & 1.00 & 1.00 \\
\hline 1,8-Cineole & 0.27 & 0.23 & 0.47 & 0.36 & 1.21 \\
\hline p-Cymene & 0.41 & 0.23 & 0.37 & 0.55 & 0.75 \\
\hline Linalool & 0.06 & 0.10 & 0.05 & 0.09 & 0.17 \\
\hline$\alpha$-Thujone & 0.29 & 0.42 & 0.31 & 0.58 & 1.03 \\
\hline$\beta$-Thujone & 8.89 & 14.59 & 8.70 & 16.06 & 25.74 \\
\hline$\alpha$-Bisabolol & 0.32 & 1.22 & 0.30 & 0.10 & 1.31 \\
\hline$\Sigma$-Terpenes ${ }^{\mathrm{a}}$ & 1.51 & 1.71 & 1.25 & 1.72 & 2.77 \\
\hline
\end{tabular}

${ }^{\text {a }} \Sigma$-Terpenes $=$ sabinene $+\beta$-pinene $+p$-cymene.

$\alpha$-phellandrene showed an intermediate quantitative composition between thujones and some other minor compounds. Only a combination of terpenes such as sabinene, $\beta$-pinene and $p$-cymene invariably prevailed over $\alpha$-phellandrene abundance, while $\alpha$-bysabolol prevailed over $\alpha$-phellandrene abundance only in a few cases. However, no determining factors were identified that could affect fluctuations of abundance index values.

In order to identify any significant differences in quantitative composition of volatile compounds, it may be more useful to compare $R_{\mathrm{n}}$ ratio values. However, data should be evaluated in view of results reported in Table 5 (for free soil) and Table 6 (for soil with Maipex mulch), where comparisons are described that may be subjected to statistical processing.

$\Delta_{\max }$ and $\Delta_{\min }$ values and mean values $(M)$ from ratios R1, R2, R3, R4, R5, R6 are reported. Both mean values $(M)$ and $\Delta_{\min }$ and $\Delta_{\max }$ of the ratios taken into account showed a random trend, which was not correlated with any factor. As a result, a non-significance of differences in analysis of volatile compounds may be assumed.

\section{CONCLUSIONS}

Data showed that, at least for $A$. absinthium L., mountain territories may be used almost without significative differentiation to produce herbs having rather comparable characteristics, though on soils at varying altitudes. As expected, data confirmed that the rate of growth of dried material may differ according to the physicochemical quality of the soil.

As confirmed by results from this research, the importance of producing plantations derived from plants of selected variety, cultivar and chemotype was obviously demonstrated.

Once again, fluctuation of indexes at different altitudes, taken into account in this work, should not be considered significant to the use of $A$. absinthium L. Based on our experiments, the extracts produced, 

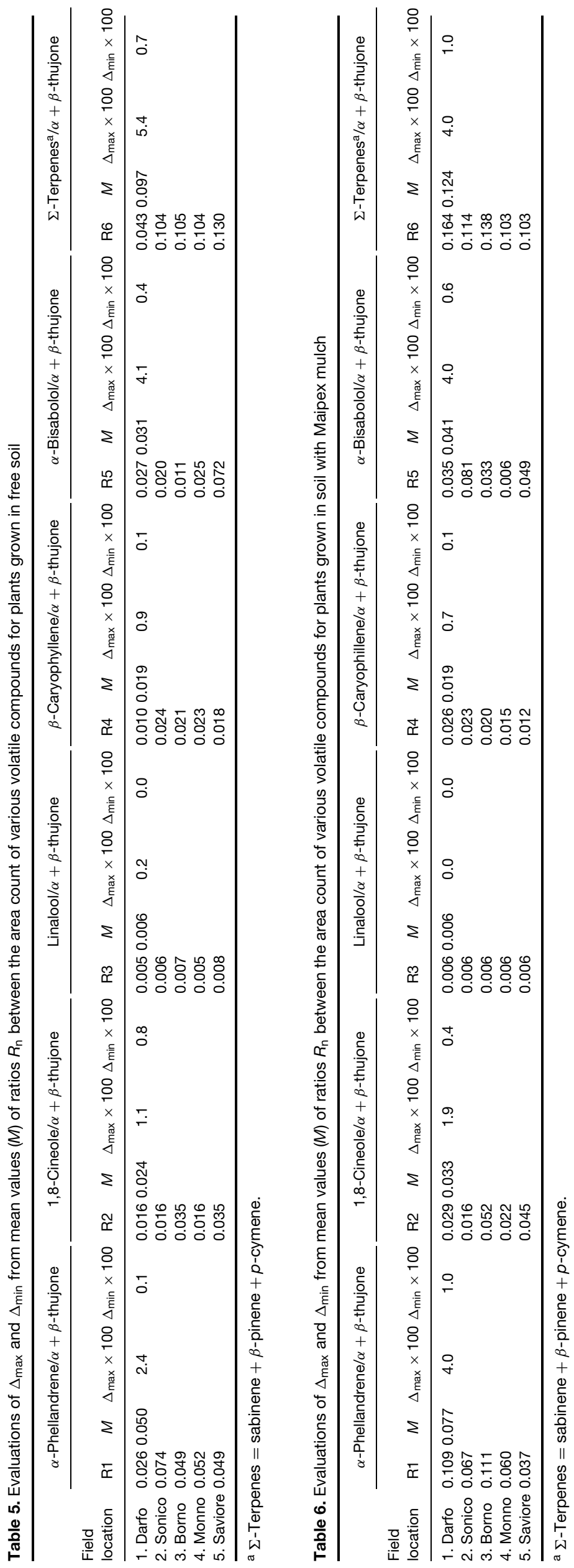
including essential oil, did not exhibit significantly different sensory characteristics.

In addition, using $A$. absinthium $\mathrm{L}$. in the sector of both alcoholic and non-alcoholic beverages can be justified by the possible use of its bittering fraction, which is complementary to the volatile fraction. Despite this, an adequately invariable composition of the volatile fraction, which was confirmed in this work, ensured that the bittering effect of the plant did not reflect a diversified sensory impact, which could have been associated with products obtained at different altitudes.

This work supplied a useful response to the production issue which suggested the research project developed by Regione Lombardia with the aim of improving mountain territories.

\section{ACKNOWLEDGEMENTS}

The present paper includes part of the results obtained from an investigation supported by Regione Lombardia, 'Development of officinal plant production in mountain environment (Valle Camonica)' DGR $7 / 9182$ of $31 / 05 / 2002$, research and development plan 2002 (2002-2005) with respect to sound improvement of mountain territories. Thanks are due to A Repossi and G Andreoli for their collaboration.

\section{REFERENCES}

1 Chialva F, Liddle PAP and Doglia G, Chemotaxonomy of wormwood (Artemisia absinthium L.). I. Composition of the essential oil of several chemotypes. $Z$ Lebensm Unters Forsch 176:363-366 (1983).

2 Mucciarelli M, Caramiello R, Maffei M and Chialva F, Essential oil from some Artemisia species growing spontaneously in north-west Italy. Flavour Frag f 10:25-32 (1995).

3 Carnat AP, Madesclaire M, Chavignon O and Lamaison JL, cisChrysanthenol, a main component of Artemisia absinthium L. growing in Auvergne (Massif Central), France. $\mathcal{F}$ Essent Oil Res 4:487-490 (1992).

4 Ariño A, Arberas I, Renobales G, Arriaga S and Dominguez JB, Essential oil of Artemisia absinthium L. from the Spanish Pyrenees. F Essent Oil Res 11:182-184 (1999).

5 Ministero per le Politiche Agricole e Forestali, Metodi di analisi chimica del suolo. Supplemento Ordinario alla Gazzetta Ufficiale-Serie Generale n. 248 del 21-10-1999 (1999).

6 Bononi M, Tateo $\mathrm{F}$ and Liuzzi V, Application of stir bar sorptive extraction (SBSE) to evaluate the volatile compounds' profile of primitivo wine. f Food Technol 3:319-325 (2005). 